\title{
TWO KINDS OF COMPOSITIONS OF HILBERT-HARDY-TYPE INTEGRAL OPERATORS AND THE RELATED INEQUALITIES
}

\author{
BICHENG YANG AND QIANG CHEN
}

Abstract. By the use of the way of Real and Functional Analysis and estimating the weight functions, we build some lemmas and deduce some Hilbert-Hardy-type integral inequalities. The equivalent forms and the reverses are all considered. Two kinds of Hilbert-Hardy-type integral operators are defined and the composition formulas of the operators are given.

Mathematics subject classification (2010): 26D10, 26D15, 40A05, 33B15.

Keywords and phrases: Hilbert-type integral inequality, weight function, equivalent form, reverse, composition of operator.

\section{REFERENCES}

[1] I. SCHUR, Bernerkungen sur theorie der beschrankten bilinearformen mit unendich vielen veranderlichen, Journal of Math., vol. 140, pp. 1-28, 1911.

[2] G. H. HARDY, Note on a theorem of Hilbert concerning series of positive term, Proccedings of the London Mathematical Sciety, vol. 23, pp. 45-46, 1925.

[3] G. H. Hardy, J. E. LitTlewood, G. Pólya, Inequalities, Cambridge University Press, Cambridge, USA, 1934.

[4] D. S. MitrinoviĆ, J. E. PeČARIĆ, A. M. FinK, Inequalities involving functions and their integrals and derivatives, vol. 53, Kluwer Academic, Boston, USA, 1991.

[5] B. YANG, On Hilbert's integral inequality, J. Math. Anal. Appl., vol. 220, pp. 778-785, 1998.

[6] B. YANG, The norm of operator and Hilbert-type inequalities, Science Press, Beijing, China, 2009.

[7] T. CARLEMAN, Sur les equations integrals singulieres a noyau reel et symetrique, Uppsala, 1923.

[8] M. Wilhelm, On the spectrum of Hilbert's inequality, Amer. J. Math., vol. 72, pp. 699-704, 1950.

[9] K. W. ZhANG, A bilinear inequality, J. Math. Anal. Appl., vol. 271, pp. 288-296, 2002.

[10] B. YANG, On the norm of an integral operator and applications, J. Math. Anal. Appl., 321, pp. 182192, 2006.

[11] B. ARPAD, O. ChOONGHONG, Best constant for certain multilinear integral operator, Journal of Inequalities and Applications, Vol. 2006, Art. ID 28582: 1-12.

[12] Q. HuAng, B. YANG, On a Multiple Hilbert-type integral operator and applications, Journal of Inequalities and Applications, Vol. 2009, Art. ID 192197: 1-13.

[13] B. YAng, M. XIE, A Hilbert-Hardy-type inequality, Applied Mathematical Science, vol. 6, no. 67, pp. 3321-3327, 2012.

[14] V. Adiyasuren, Ts. Batbold, M. Krnić, On several new Hilbert-type inequalities involving means operators, Acta Mathematica Sinica, English Series, vol. 29, no. 8, pp. 1493-1514, 2013.

[15] X. LiU, B. YANG, On a new Hilbert-Hardy-type integral operator and applications, Journal of Inequalities and Applications, Vol. 2010, Art. ID 812636: 1-10.

[16] V. Adiyasuren, Ts. BATBold, M. Krnić, Half-discrete Hilbert-type inequalities with mean operators, the best constants, and applications, Applied Mathematics and Computation, vol. 231, pp. 148-159, 2014.

[17] B. YANG, Hilbert-type integral inequalities, Bentham Science Publishers Ltd., The United Arab Emirates, 2009.

[18] J. KuANG, Introudction to Real Analysis, Hunan Educaton Press, Changsha, China, 1996.

[19] J. KuAng, Applied inequalities, Shangdong Science and Technology Press, Jinan, China, 2004. 
[20] A. E. TAYLOR, D. C. LAY, Introduction to functional analysis, Wiley, New York, USA, 1980. 